\title{
Individual Differences in Conceptual and Procedural Fraction Knowledge: What Makes the Difference and What Does it Look Like?
}

\author{
Katja Lenz ${ }^{1 \star(D)}$, Gerald Wittmann ${ }^{1}$ (D)
}

${ }^{1}$ University of Education Freiburg, Kunzenweg 21, 79117 Freiburg, GERMANY

*Corresponding Author: katja.lenz@ph-freiburg.de

Citation: Lenz, K., \& Wittmann, G. (2021). Individual Differences in Conceptual and Procedural Fraction Knowledge: What Makes the Difference and What Does it Look Like?. International Electronic Journal of Mathematics Education, 16(1), em0615. https://doi.org/10.29333/iejme/9282

\begin{abstract}
ARTICLE INFO
Received: 23 Apr. 2020

Accepted: 30 Jul. 2020

ABSTRACT

There is a general consensus that both conceptual and procedural knowledge are essential for students' mathematical development. A common argument is that differences in mathematical performance are caused by differences in conceptual and procedural knowledge. Therefore, it is important to investigate to what extent such differences in conceptual and procedural knowledge are empirically evident at the level of individual students. Accordingly, the aim of the present study is to describe individual differences in conceptual and procedural knowledge using the example of fractions and to analyze their relationship to the covariates grade level, school type, school, class, gender, and general cognitive abilities. Data from 377 students in grades 8 and 9 from 18 classes at four schools in Germany was examined. A hierarchical cluster analysis showed five clusters which reflected individual differences in conceptual and procedural knowledge. The clusters were characterized by (a) equal strengths in conceptual and procedural knowledge, (b) relative strengths in procedural knowledge compared to conceptual knowledge, (c) relative weaknesses in procedural knowledge compared to conceptual knowledge. Cluster membership was not related to gender or grade level, whereas the school type, school, and grade level were relevant for cluster membership. A stronger correlation between conceptual knowledge and general cognitive abilities could only be confirmed to a limited extent.
\end{abstract}

Keywords: fractions, individual differences, conceptual knowledge, procedural knowledge, cluster analysis

\section{INTRODUCTION}

The distinction between conceptual and procedural knowledge as two different types of knowledge is found in psychology (e.g., Anderson, Funke, Neuser-von Oettingen, \& Plata, 2013; Anderson \& Krathwohl, 2001; Rittle-Johnson \& Schneider, 2015) as well as in mathematics education (Geary, 2004; Geary et al., 2008; Hiebert \& Lefevre, 1986). Conceptual knowledge is commonly defined as knowledge of concepts and principles which are fundamental in a certain domain (Byrnes \& Wasik, 1991; Hiebert \& Lefevre, 1986; Kilpatrick, Swafford, \& Findell, 2001) and knowledge of why a mathematical procedure works (Crooks \& Alibali, 2014; Kilpatrick et al., 2001). Conceptual knowledge of fractions involves knowing special characteristics of fractions (e.g., relation of numerator and denominator, density of fractions) and various aspects of fractions (e.g., Kieren, 1976; Malle, 2004; Padberg \& Wartha, 2017). Procedural knowledge is defined as knowledge of how a procedure works. It is the knowledge of a sequence of steps or partial actions which are performed to achieve a specific goal (Byrnes \& Wasik, 1991; Hiebert \& Lefevre, 1986; Malle, 2004; Prediger, Barzel, Leuders, \& Hußmann, 2011; Rittle-Johnson, Siegler, \& Alibali, 2001). Procedural knowledge of fractions is highly complex, as fractions are processed differently in the calculation procedures. For example, the multiplication of fractions allows a component-wise processing of numerator and denominator, which is not possible for addition and subtraction.

As the definitions suggest, conceptual and procedural knowledge are closely interrelated. Accordingly, previous studies have found substantial positive correlations between them (e.g., Rittle-Johnson \& Schneider, 2015). These strong positive correlations raise the question whether conceptual and procedural knowledge can be separated empirically at all. Consequently, previous studies have addressed the empirical separability, analyzing conceptual and procedural knowledge on a latent level (Hecht, Close, \& Santisi, 2003; Lenz, Dreher, Holzäpfel, \& Wittmann, 2019a). In particular, confirmatory factor analyses were conducted to determine whether conceptual knowledge and procedural knowledge represent two distinct dimensions by means of model comparisons. The results showed a substantial loss in the fit of the model to the data when a one-factor model was specified instead of a two-factor model. Therefore, it has been assumed that conceptual and procedural knowledge are two different types of knowledge that can be separated both theoretically and empirically.

As the relationship between conceptual and procedural knowledge is not sufficiently clarified so far (Rittle-Johnson \& Schneider, 2015; Vamvakoussi, Bempeni, Poulopoulou, \& Tsiplaki, 2019), the aim of this study is to describe individual differences 
in conceptual and procedural fraction knowledge in more detail and to analyze their relationship to relevant factors. Fractions are a challenge for both students and mathematics teachers throughout the world (Lortie-Forgues, Tian, \& Siegler, 2015) and there is consensus among researchers that the distinction between conceptual and procedural knowledge is important in understanding and remedying these problems (e.g., Gabriel, Coché, Szucs, Carette, Rey, \& Content, 2013; Rittle-Johnson \& Schneider, 2015; Siegler \& Lortie-Forgues, 2015).

\section{THEORETICAL FRAMEWORK}

Concerning how conceptual and procedural knowledge develops, there are three different theoretical assumptions, each supported by empirical findings: (1) procedures first, (2) concepts first, and (3) iterative (Rittle-Johnson \& Schneider, 2015). These approaches are described in more detail below, taking into account empirical results primarily in the field of fractions.

The procedures first approach assumes that procedural knowledge is the basis for the development of conceptual knowledge. It states that learners can recognize underlying mathematical concepts and principles when executing a procedure repeatedly and acquire conceptual knowledge that way. Empirical studies have confirmed that procedural knowledge precedes conceptual knowledge. In the field of fractions, learners applied procedural knowledge without conceptual knowledge though they were not able to explain why the procedures work this way (Kerslake, 1986; Peck \& Jencks, 1981). Young children performed the counting procedure without having conceptual knowledge about counting principles (Baroody \& Gannon, 1984; Briars \& Siegler, 1984).

The concepts first approach conversely says that conceptual knowledge is the prerequisite for developing procedural knowledge, which is also supported by empirical evidence. In the field of fraction addition, conceptual knowledge can predict procedural knowledge but not vice versa (Byrnes \& Wasik, 1991). In the field of addition and subtraction of multi-digit numbers, conceptual knowledge in the first class can predict procedural knowledge at the same time as well as procedural knowledge at a later time of measurement (Hiebert \& Wearne, 1996).

Mediating between the first two approaches, the iterative approach assumes that conceptual and procedural knowledge develop mutually interdependently. An improvement in one type of knowledge causes an improvement in the other type, and vice versa. This approach is also substantiated by empirical evidence. With regard to decimal fractions, procedural knowledge at pretest predicted conceptual knowledge at posttest, and analogously conceptual knowledge at pretest predicted procedural knowledge at posttest (Rittle-Johnson et al., 2001). While some studies have shown symmetrical effects regarding the relationship between the two types of knowledge (e.g., Schneider, Rittle-Johnson, \& Star, 2011 for linear equations), numerous empirical findings in the field of fractions suggest that conceptual knowledge has a greater effect on the development of procedural knowledge than vice versa (Byrnes \& Wasik, 1991; Fuchs et al., 2013; Hecht \& Vagi, 2010; Rittle-Johnson et al., 2001).

As the empirical results described above are based on correlations, they reflect the relationship between conceptual and procedural knowledge at a group level. However, they cannot answer the question of how this relationship behaves at the individual level (Vamvakoussi et al., 2019).

Another line of research deals with individual differences in conceptual and procedural knowledge and aims on knowledge profiles which describe the relationship of conceptual and procedural knowledge by means of cluster analysis for groups of learners. Studies have identified clusters of students whose levels of conceptual and procedural knowledge are equally high or low. However, there were also groups of students who showed different levels of conceptual and procedural knowledge, i.e. more or less procedural knowledge than could have been expected from their conceptual knowledge or vice versa (Bempeni, Poulopoulou, Tsiplaki, \& Vamvakoussi, 2018; Hallett, Nunes, \& Bryant, 2010; Hallett, Nunes, Brynt, \& Thorpe, 2012; Hecht \& Vagi, 2012). These findings indicate that conceptual and procedural knowledge develop differently at the individual level.

Research on the causes of these individual differences is scarce and has not yet led to conclusive results. Three aspects are discussed in more detail below: (1) learning experiences, (2) general cognitive abilities, and (3) gender. Regarding the students' learning experiences there are ambiguous findings. While some results indicate an effect of the attended school on individual differences in conceptual and procedural knowledge, this effect was not visible in other results (Hallett et al., 2010, 2012). With respect to general cognitive abilities, empirical studies unveil higher correlations between conceptual knowledge and general cognitive abilities than between procedural knowledge and general cognitive abilities (e.g., Jordan et al., 2013). Thus, it seems plausible that students with higher general cognitive abilities have particular advantages in developing conceptual knowledge, but there is no clear empirical evidence for this hypothesis (e.g. Hallett et al., 2012). Regarding gender, there is no theoretical basis for assuming an impact on individual differences in conceptual and procedural knowledge. Nevertheless, there are empirical findings that indicate an effect of gender on individual differences in conceptual and procedural fraction knowledge for younger students but not for older ones (Hallett et al., 2010, 2012).

\section{RESEARCH QUESTIONS}

Concerning students' difficulties with fractions, many explanatory approaches are based on the distinction between conceptual knowledge and procedural knowledge. To get further insight into reasons and remedies for these difficulties, it is thus necessary to examine individual differences in conceptual and procedural fraction knowledge in more detail and to analyze their relationship to different factors. Specifically, the following two research questions are investigated:

1) Are there individual differences in students' conceptual and procedural fraction knowledge and what do they look like?

2) Are these individual differences related to the factors grade level, school type, school, class, general cognitive abilities and gender? 


\section{METHODOLOGY}

\section{Participants and Procedure}

In this study $N=377$ German 8th- and 9th-graders from 18 classes of four secondary schools located in various regions were examined. Of these four schools, two were Realschule $(n=235)$, two were Gymnasium $(n=142)$. The Realschule offers a comprehensive general education and is mainly aimed at vocational qualifications; it is intended for students with an average level of academic performance. The Gymnasium is the more advanced school type and provides a broader and deeper general education; it is intended for students with above average level of academic performance. One of the two schools belonging to Gymnasium even has a special profile in the field of gifted education. All these aspects considered, the sample maximizes the individual differences in learning experiences and general cognitive abilities.

In Germany, fractions are usually taught in 6th grade. Therefore, it can be assumed that students in the 8th and 9th grade have completed their course, and thus have a stable fractional knowledge acquired over the long term. Hence, no short-term effects are measured. In addition, the higher-grade levels seem to be particularly interesting with regard to individual differences in conceptual and procedural knowledge, since it is assumed that the differences in the two types of knowledge decrease with increasing expertise (Baroody, Feil, \& Johnson, 2007; Hallett et al., 2012). If this is the case, individual differences in conceptual and procedural knowledge should be common when students first encounter fractions, but not in grades 8 and 9 .

The data was collected in a whole-class setting. Participants were randomly assigned to one of four test versions containing the same items but in different order. Their regular teachers administered the data collection following a standardized procedure.

\section{Measures}

The assessment was conducted in written form and consisted of three parts: (1) a test of conceptual and procedural fraction knowledge, (2) a test of general cognitive abilities and, additionally, (3) a personal questionnaire (grade level, type of school, gender). Hereafter, the two test instruments are described in more detail.

To assess conceptual and procedural fraction knowledge, a test instrument was used which has been extensively validated (Lenz et al., 2019a). It comprises 37 items, 18 of which are on the procedural subscale (Cronbach's alpha $a=.90$ ) and 19 on the conceptual subscale (Cronbach's alpha $\alpha=.88$ ) (see Table 1). Since the intended test use is to investigate conceptual and procedural fraction knowledge independently of each other, fraction tasks which can be solved using conceptual as well as procedural knowledge (e.g., size comparison tasks) or which require both types of knowledge (e.g., word problems) are not included in this test instrument. Thus, the test instrument does not assess overall fraction performance, but is specifically for the differentiated measurement of conceptual and procedural knowledge. The conceptual knowledge subscale contains three different task types:

1) tasks requiring the verbalization of conceptual knowledge, e.g., to write explanations (C1_verbalization);

2) tasks addressing the application of conceptual knowledge, e.g., number line tasks to assess the application of the measurement aspect (C2_application);

3) tasks requiring the visualization of conceptual knowledge, e.g., to draw a visualization or shade a figure to match a given fraction in symbolic form (C3_visualization).

Table 1. Test instrument for assessing conceptual and procedural knowledge

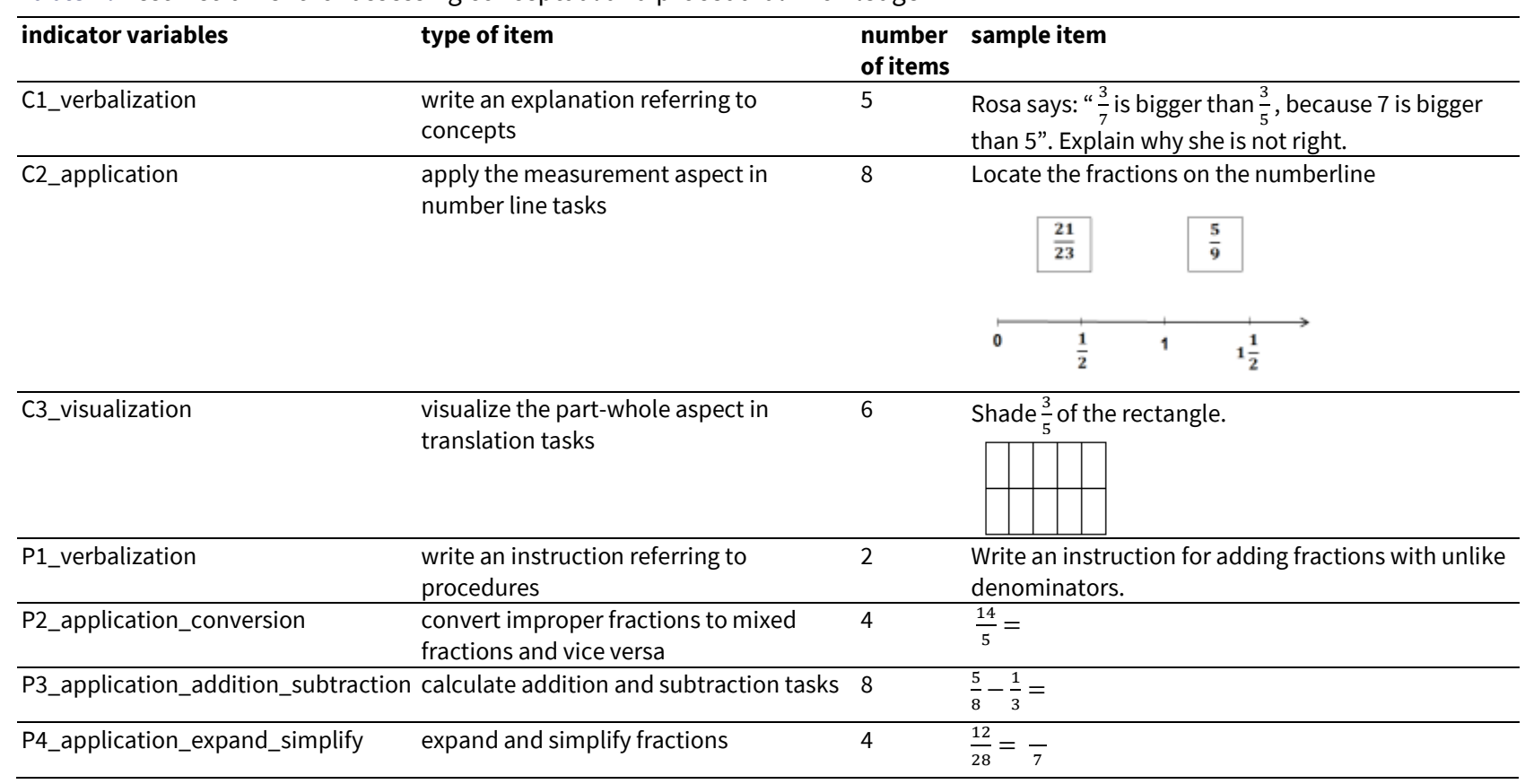


The subscale for procedural knowledge comprises two task types, wherein the tasks requiring the application of procedural knowledge are divided into three subtypes:

1) tasks requiring the verbalization of procedural knowledge, e.g., writing instructions concerning a calculation procedure (P1_verbalization);

2) tasks requiring the application of procedural knowledge, e.g.,

- converting improper fractions into mixed fractions, and vice versa (P2_application_conversion),

- adding or subtracting fractions (P3_application_addition_subtraction),

- expanding and simplifying fractions (P4_application_expanding_simplifying).

The task type P3_application_addition_subtraction includes tasks of the following kinds: (a) proper fractions with same denominators; (b) proper fractions with different denominators and one denominator being a multiple of the other; (c) proper fractions with different denominators which are not multiples of each other; (d) a proper fraction and a whole number.

Concerning the second research question, cognitive abilities were assessed as a covariate using the "Figural Analogies B" subscale of the "KFT 4-12 + R" (Heller \& Perleth, 2000), a German version of the "Cognitive Abilities Test" (Thorndike \& Hagen, 1971). The subscale consists of 25 items in multiple-choice format. It requires drawing correct analogies by understanding relationships between two presented figures and transferring them to another pair of figures. This subscale grasps a highly gloaded ability component which is little influenced by school learning (Holling, Preckel, \& Vock, 2004). The internal consistency of the subscale was estimated according to the Kuder-Richardson formula 20 (Lienert, 1969, p. 226-227) based on item difficulties, discriminatory power, and standard deviation. The internal consistency was .90 for 8 th grade and .85 for 9 th grade. Retest reliability was .93 for 8 th grade and .90 for 9 th grade (Heller \& Perleth, 2000, p. 20-21).

\section{Data Analysis}

For data analysis the Statistical Package for the Social Sciences (SPSS 24) was used.

Students' responses were scored dichotomously (0: incorrect, fragmentary, or missing; 1: correct). To test intercoder reliability, about $10 \%$ of the data was coded by a second person. The degree of agreement was determined using Cohen's kappa for each item, which represents the degree of concordance in coding, while controlling for chance agreement. Adequate intercoder reliability was obtained with $0.823 \leq \kappa \leq 1$ for all items.

As cluster analyses are well established to describe individual differences in conceptual and procedural knowledge, a hierarchical cluster analysis was conducted. Following previous research on individual differences in fraction knowledge, Ward's method and residualized scores were used (e.g., Hallett, 2010, 2012; Hecht \& Vagi, 2012). Residualized scores describe individual differences in terms of the discrepancy between expected and observed scores, which allows to eliminate shared variance between conceptual and procedural knowledge (Cohen, Cohen, West, \& Aiken, 2013). This makes sense because conceptual and procedural knowledge are usually highly correlated (e.g., Hallett et al., 2010; Lenz et al., 2019a; Schneider \& Stern, 2010). As residualized scores represent relative scores and not absolute scores, a more precise description of the identified clusters based on students' performance in the test is not possible. Since this study aims at an in-depth description of individual differences in conceptual and procedural knowledge, the residual scores were not used for both types of knowledge, but only for procedural knowledge.

In detail, the following procedures were implemented. The sum scores of the procedural and the conceptual scale were zstandardized. Based on the assumption that conceptual knowledge influences procedural knowledge more than vice versa (as stated above), a linear regression with procedural knowledge as dependent variable and conceptual knowledge as predictor variable was conducted. The residual scores for procedural knowledge calculated by the linear regression represent relative scores which indicate a strength or weakness in procedural knowledge relative to conceptual knowledge. Accordingly, a positive residual score indicates that a person has more procedural knowledge than would have been expected from his or her conceptual knowledge. Conversely, a negative residual score indicates that a person has less procedural knowledge than would have been expected from his or her conceptual knowledge.

For an in-depth understanding of the individual differences, the descriptive statistics of the task types (mean values, standard deviations) were analyzed. One-way analysis of variance (ANOVA) was used to compare the mean values. In addition, a Chi-square test was used to investigate whether distributions of different profiles were related to the factors grade level, school type, school, class, or gender. Finally, a one-way ANOVA was conducted to assess the effects of general cognitive abilities on cluster membership. In case of homogeneity of variance (Levene's test, $p>.05$ ), Bonferroni post-hoc analyses were run. Otherwise, where there was insufficient homogeneity of variance, a Welch ANOVA and the Games-Howell post-hoc test were used. 


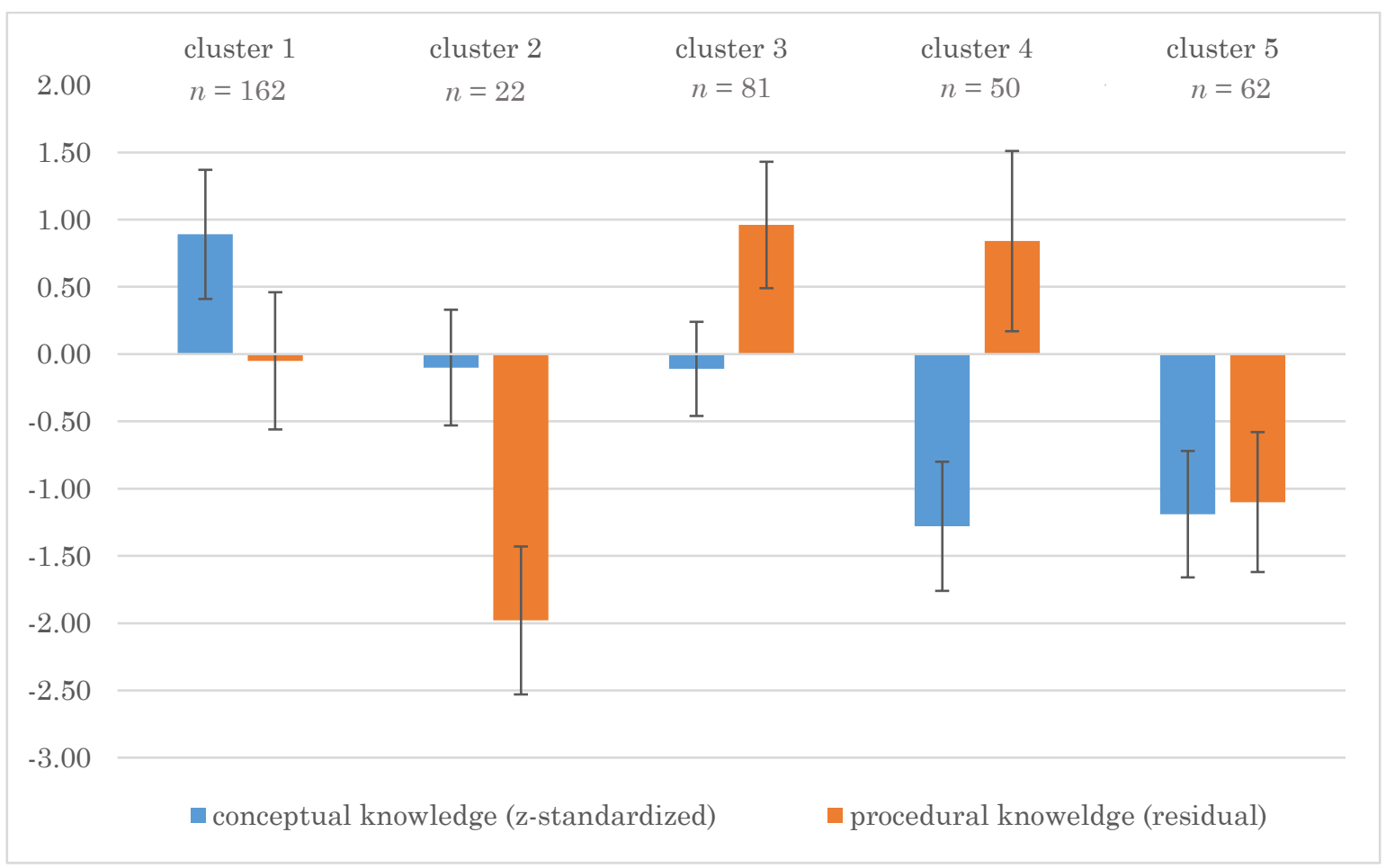

Figure 1. Results of the cluster analysis. Note: Error bars represent the standard deviations.

Table 2. Descriptive statistics by cluster membership

\begin{tabular}{|c|c|c|c|c|c|c|c|c|c|c|}
\hline & \multicolumn{2}{|c|}{ cluster 1} & \multicolumn{2}{|c|}{ cluster 2} & \multicolumn{2}{|c|}{ cluster 3} & \multicolumn{2}{|c|}{ cluster 4} & \multicolumn{2}{|c|}{ cluster 5} \\
\hline & \multicolumn{2}{|c|}{$n=162$} & \multicolumn{2}{|c|}{$n=22$} & \multicolumn{2}{|c|}{$n=81$} & \multicolumn{2}{|c|}{$n=\mathbf{5 0}$} & \multicolumn{2}{|c|}{$n=62$} \\
\hline & $M$ & (SD) & $M$ & (SD) & $M$ & (SD) & $M$ & (SD) & $M$ & (SD) \\
\hline conceptual knowledge (z-standardized) & .89 & $(.48)$ & -.10 & $(.43)$ & -.11 & $(.35)$ & -.11 & $(.35)$ & -1.19 & $(.47)$ \\
\hline procedural knowledge (residual) & -.05 & $(.51)$ & -1.98 & $(.55)$ & .96 & $(.47)$ & .96 & $(.47)$ & -1.10 & $(.52)$ \\
\hline
\end{tabular}

Note: $n=$ number of students in the cluster; $M=$ mean value; $S D=$ standard deviation

\section{RESULTS}

\section{Results of the Cluster Analysis and Cluster Characterization}

The hierarchical cluster analysis provided a five-cluster solution, according to the dendrogram and the coefficients of the assignment overview (Bühl, 2016; Wiedenbeck \& Züll, 2010). The determined clusters (see Figure 1 and Table 2) can be described as having different levels of conceptual and procedural knowledge. These are the identified clusters in descending order of conceptual knowledge:

1) high conceptual knowledge and equally high procedural knowledge (cluster 1),

2) average conceptual knowledge and lower procedural knowledge than would have been expected from conceptual knowledge (cluster 2),

3) average conceptual knowledge and higher procedural knowledge than would have been expected from conceptual knowledge (cluster 3),

4) low conceptual knowledge and higher procedural knowledge than would have been expected from conceptual knowledge (cluster 4),

5) low conceptual knowledge and lower procedural knowledge than would have been expected from conceptual knowledge (cluster 5).

Cluster 1 was the only cluster with an equal level of conceptual and procedural knowledge while the other four clusters represented different levels of conceptual and procedural knowledge: Cluster 2 and cluster 5 contained students who had on average lower procedural knowledge than would have been expected from their conceptual knowledge, whereas cluster 3 and cluster 4 contained students who had on average higher procedural knowledge than would have been expected from their conceptual knowledge. 


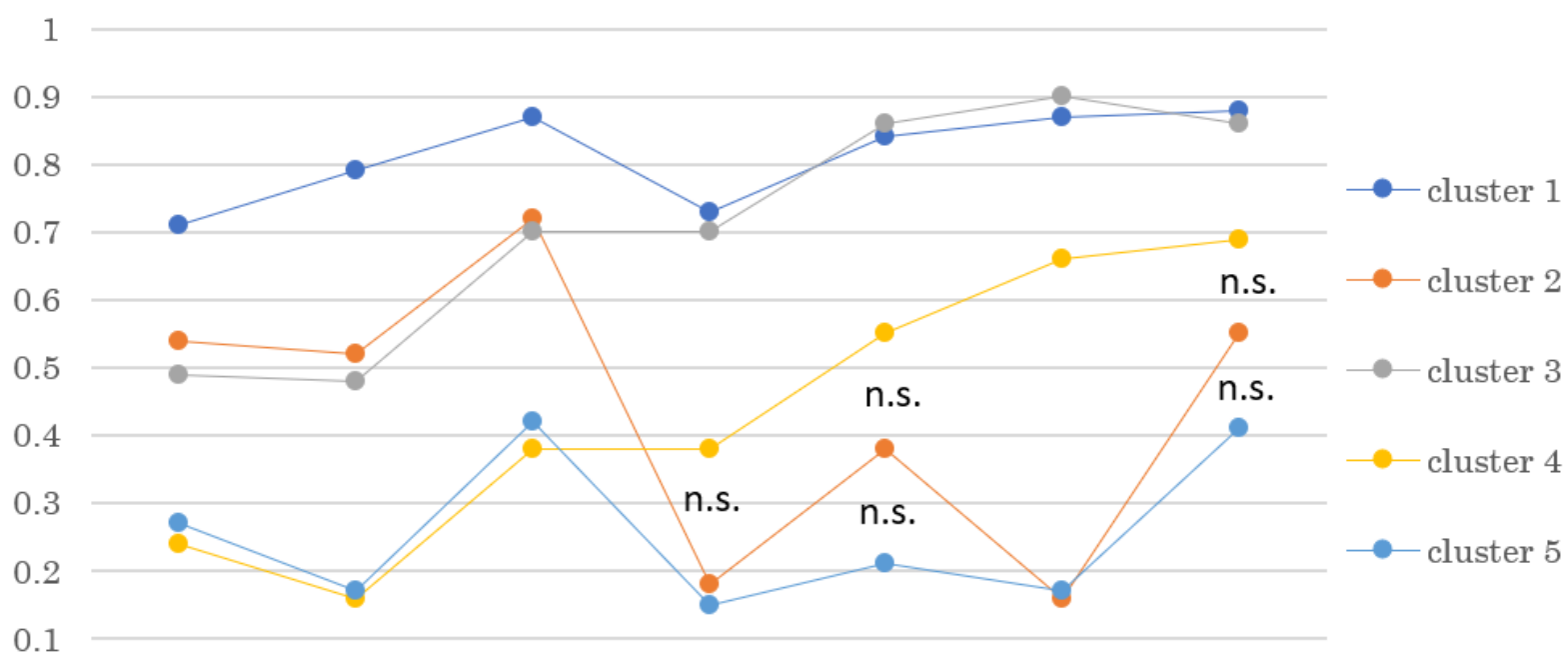

0
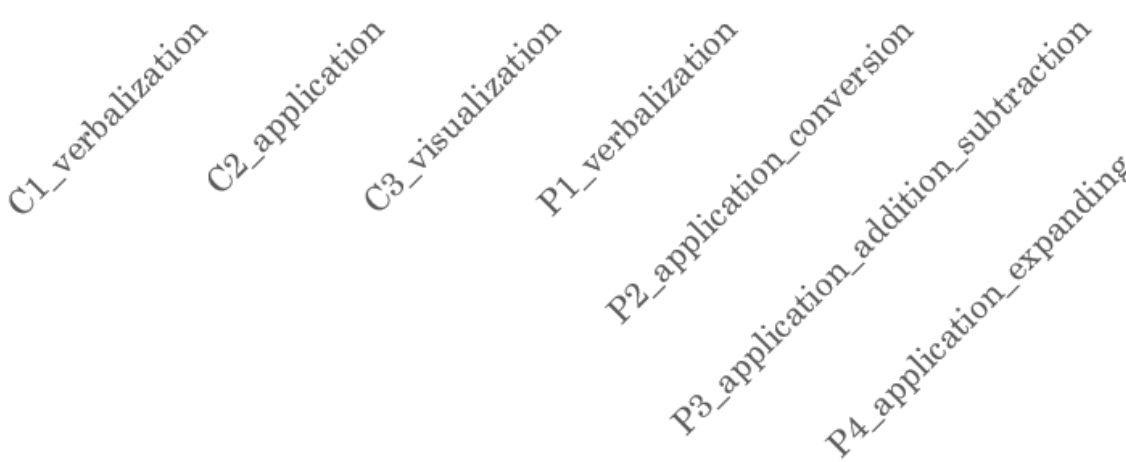

Figure 2. Mean levels of accuracy by cluster membership. Note: Non-significant differences $(p>0.05)$ which are not evident are indicated by the abbreviation n.s.

Table 3. Mean level of accuracy by cluster membership

\begin{tabular}{|c|c|c|c|c|c|c|c|c|c|c|}
\hline & \multicolumn{2}{|c|}{$\begin{array}{l}\text { cluster } 1 \\
(n=162)\end{array}$} & \multicolumn{2}{|c|}{$\begin{array}{c}\text { cluster } 2 \\
(n=22)\end{array}$} & \multicolumn{2}{|c|}{$\begin{array}{c}\text { cluster } 3 \\
(n=81)\end{array}$} & \multicolumn{2}{|c|}{$\begin{array}{c}\text { cluster } 4 \\
(n=50)\end{array}$} & \multicolumn{2}{|c|}{$\begin{array}{c}\text { cluster } 5 \\
(n=62)\end{array}$} \\
\hline & $M$ & $(S D)$ & $M$ & $(S D)$ & $M$ & $(S D)$ & $M$ & $(S D)$ & $M$ & $(S D)$ \\
\hline C1_verbalization & .71 & $(.20)$ & .54 & $(.25)$ & .49 & $(.21)$ & .24 & $(.20)$ & .27 & $(.22)$ \\
\hline C2_application & .79 & $(.20)$ & .52 & $(.25)$ & .48 & $(.21)$ & .16 & $(.17)$ & .17 & $(.17)$ \\
\hline C3_visualization & .87 & $(.13)$ & .72 & $(.18)$ & .70 & $(.21)$ & .38 & $(.19)$ & .42 & $(.23)$ \\
\hline P1_verbalization & .73 & $(.40)$ & .18 & $(.36)$ & .70 & $(.42)$ & .38 & $(.44)$ & .15 & $(.31)$ \\
\hline P2_application_conversion & .84 & $(.27)$ & .38 & $(.37)$ & .86 & $(.27)$ & .55 & $(.35)$ & .21 & $(.28)$ \\
\hline P3_application_addition_subtraction & .87 & $(.20)$ & .16 & $(.23)$ & .90 & $(.12)$ & .66 & $(.23)$ & .17 & $(.19)$ \\
\hline P4_application_expanding_simplifying & .88 & $(.18)$ & .55 & $(.27)$ & .86 & $(.17)$ & 69 & $(.27)$ & .41 & $(.30)$ \\
\hline
\end{tabular}

Note: $n=$ number of students in the cluster; $M=$ mean value; $S D=$ standard deviation

The clusters differed in size: Cluster 1 was the largest $(n=162)$ and cluster 2 the smallest $(n=22)$, with three mid-sized clusters ( $n=81, n=50, n=62$ ). As the descriptive statistics showed (see Figure 2 and Table 3), there were similarities and differences between students with individual differences regarding the various task types. As expected, the students in cluster 1 showed a relatively high performance across all task types. These performances differed significantly from the performances of the other clusters.

Cluster 2 and cluster 3 showed similar mean solution rates for task types assessing conceptual knowledge, whereas the clusters differed significantly in the mean solution rates of the task types assessing procedural knowledge. In particular, cluster 2 showed lower average solution rates for the task types verbalization of procedural knowledge ( $\mathrm{P} 1$ _verbalization) and applying procedural knowledge with regard to fraction addition and subtraction (P3_application_addition_subtraction).

For cluster 4 and cluster 5, a parallel pattern was observed regarding the three task types assessing conceptual knowledge, while there were significant differences in the four task types assessing procedural knowledge. Cluster 4 showed higher mean solution rates for the application of procedural knowledge, whereas students in cluster 5 showed poor performance across all task types.

As expected the mean response accuracy for the conceptual task types $(\mathrm{C} 1$ to $C 3)$ differed statistically significant $\left(F_{\mathrm{C} 1}(4,372)=\right.$ 79.24, $p<0.001, \eta^{2}=.46 ; F_{\mathrm{C} 2}(4,372)=167.01, p<0.001, \eta^{2}=.64$; Welch's $\left.F_{\mathrm{C} 3}(4,94.97)=112.92, p<0.001, \eta^{2}=.55\right)$. The post-hoc analyses (see Table 4) revealed that these significant differences were found between the clusters with high, average and low conceptual knowledge, while there were no significant differences between the clusters with similar levels of conceptual 
Table 4. Results of the Post-hoc analysis

\begin{tabular}{|c|c|c|c|c|c|c|c|c|}
\hline & \multicolumn{8}{|c|}{ mean differences } \\
\hline & C1 & C2 & C3 & P1 & P2 & P3 & P4 & gca \\
\hline cluster 1 - cluster 2 & $.17^{\star \star}$ & $.27^{*}$ & $.15^{\star \star}$ & $.55^{\star \star \star}$ & $.47^{\star \star \star}$ & $.71^{\star \star \star}$ & $.33^{\star \star \star}$ & $4.70^{\star}$ \\
\hline cluster 1 - cluster 3 & $.22^{\star \star \star}$ & $.31^{\star}$ & $.17^{\star \star \star}$ & .03 & -.02 & -.03 & .019 & $2.97^{\star \star \star}$ \\
\hline cluster 1 - cluster 4 & $.48^{\star \star \star}$ & $.63^{*}$ & $.49^{\star \star \star}$ & $.35^{\star \star \star}$ & $.29^{\star \star \star}$ & $.21^{\star \star \star}$ & $.19^{\star \star \star}$ & $6.78^{\star \star \star}$ \\
\hline cluster 1 - cluster 5 & $.44^{\star \star \star}$ & $.63^{*}$ & $.45^{\star \star \star}$ & $.58^{\star \star \star}$ & $.64^{* \star \star}$ & $.70^{* \star \star}$ & $.47^{\star \star \star}$ & $6.10^{\star \star \star}$ \\
\hline cluster 2 - cluster 3 & .05 & $.36^{\star}$ & .02 & $-.52^{\star \star \star}$ & $-.49^{\star \star \star}$ & $-.74^{\star \star \star}$ & $-.31^{\star \star \star}$ & -1.73 \\
\hline cluster 2 - cluster 4 & $.31^{\star \star \star}$ & $.36^{*}$ & $.34^{\star \star \star}$ & -.20 & -.18 & $-.50^{\star \star \star}$ & -.14 & 2.09 \\
\hline cluster 2 - cluster 5 & $.27^{\star \star \star}$ & $.36^{*}$ & $.30^{\star \star \star}$ & .03 & .17 & -.01 & .14 & 1.40 \\
\hline cluster 3 - cluster 4 & $.25^{\star \star \star}$ & $.32^{*}$ & $.32^{\star \star \star}$ & $.32^{\star \star \star}$ & $.31^{\star \star \star}$ & $.24^{\star \star \star}$ & $.17^{\star \star}$ & $3.81^{\star \star \star}$ \\
\hline cluster 3 - cluster 5 & $.22^{\star \star \star}$ & $.32^{\star}$ & $.28^{\star \star \star}$ & $.55^{\star \star \star}$ & $.66^{\star \star \star}$ & $.73^{\star \star \star}$ & $.45^{\star \star \star}$ & $3.13^{\star \star}$ \\
\hline cluster 4 - cluster 5 & -.03 & -.01 & -.04 & $.23^{\star}$ & $.34^{\star \star \star}$ & $.49^{\star \star \star}$ & $.28^{\star \star \star}$ & -.69 \\
\hline
\end{tabular}

Note. $\mathrm{C} 1$ = C1_verbalization; C2 = C2_application; C3 = C3_visualization; P1 = P1_verbalization; P2 = P2_application_conversion; P3 = P3_application_addition_subtraction; P4 = P4_application_expand_simplify; gca = general cognitive abilities. The difference of the mean values is significant at the level ${ }^{\star} p<0.05 ;{ }^{\star \star} p<0.01 ;{ }^{\star \star \star} p<0.001$

knowledge. Specifically, the mean scores in the conceptual task types for cluster 1 differed significantly from the mean scores of the other clusters. In addition, the mean scores of the conceptual task types for cluster 2 and cluster 3 were significantly different from the mean scores of the conceptual task types for cluster 4 and cluster 5 . The pairwise comparison for both cluster 2 and 3 and cluster 4 and 5 was non-significant.

For the procedural task types ( $\mathrm{P} 1$ to $\mathrm{P} 4)$ there were also statistically significant differences between the mean response accuracy of the different clusters (Welch's $F_{\mathrm{P} 1}(4,102.94)=42.19, p<0.001, \eta^{2}=.27$; Welch's $F_{\mathrm{P} 2}(4,97.77)=72.08, p<0.001, \eta^{2}=.44$; Welch's $F_{\mathrm{P} 3}(4,98.44)=218.66, p<0.001, \eta^{2}=.70$; Welch's $\left.F_{\mathrm{P} 4}(4,95.09)=42.01, p<0.001, \eta^{2}=.40\right)$. The post-hoc analyses showed that cluster 1 and cluster 3 differed significantly from the other clusters, indicating a higher performance across all procedural tasks. Furthermore, the mean score for P3_addition_subtraction of cluster 4 differed significantly from the mean scores of cluster 2 and cluster 5 while other pairwise comparisons between these clusters were non-significant. This indicates that considerable differences exist between these clusters that affect the processing of fraction addition and subtraction.

\section{Relationship between Cluster Membership and Affecting Factors}

\section{Gender and learning experiences}

To answer research question 2, possible explanations for the identified individual differences in conceptual and procedural knowledge were explored. The distribution of students among the clusters is shown in Table 5.

Cluster membership is independent of

- $\quad$ gender $\left(\chi^{2}(8)=12.13, p=.146\right)$, and

- $\quad$ grade level $\left(\chi^{2}(4)=4.34, p=.362\right)$.

Obviously, individual differences in conceptual and procedural knowledge cannot be explained by students' gender. There were also no effects of grade level on cluster membership. This seems plausible as both 8th and 9th graders have already fully absolved the course on fractions and therefore no fundamental differences in fraction knowledge were expected between them.

In contrast, cluster membership is not independent of

- $\quad$ school type $\left(\chi^{2}(4)=69.402, p<.001\right)$,

- $\operatorname{school}\left(\chi^{2}(12)=99.787, p<.001\right)$, and

- $\operatorname{class}\left(\chi^{2}(68)=179.539, p<.001\right)$.

Overall, these results provide evidence for the hypothesis that individual differences in conceptual and procedural knowledge are related to different learning experiences. It appears particularly interesting that effects at school and class level cannot be fully explained by the effects of the school type. The distributions of the clusters within the sub-sample of Realschule and the subsample of Gymnasium were also dependent on the school attended (Realschule: $\chi^{2}(4)=28.266, p<.001$; Gymnasium: $\chi^{2}(4)=$ $18.278, p<.001)$. Furthermore, there were class effects within the sub-sample of Realschule $\left(\chi^{2}(36)=70.551, p<.001\right)$, but not within the sub-sample of Gymnasium $\left(\chi^{2}(28)=36,327, p<.134\right)$. 
Table 5. Cluster distribution

\begin{tabular}{|c|c|c|c|c|c|}
\hline & $\begin{array}{l}\text { cluster } 1 \\
(n=162)\end{array}$ & $\begin{array}{c}\text { cluster } 2 \\
(n=22)\end{array}$ & $\begin{array}{c}\text { cluster } 3 \\
(n=81)\end{array}$ & $\begin{array}{c}\text { cluster } 4 \\
(n=50)\end{array}$ & $\begin{array}{c}\text { cluster } 5 \\
(n=62)\end{array}$ \\
\hline \multicolumn{6}{|l|}{ gender } \\
\hline male $(n=216)$ & 87 & 16 & 51 & 25 & 37 \\
\hline female $(n=161)$ & 75 & 6 & 30 & 25 & 25 \\
\hline \multicolumn{6}{|l|}{ grade level } \\
\hline 8 th grade $(n=215)$ & 84 & 11 & 51 & 31 & 38 \\
\hline 9th grade $(n=162)$ & 78 & 11 & 30 & 19 & 24 \\
\hline \multicolumn{6}{|l|}{ type of school, school, class } \\
\hline Realschule $(n=235)$ & 68 & 19 & 48 & 43 & 57 \\
\hline school A $(n=128)$ & 52 & 6 & 30 & 20 & 20 \\
\hline class A-8a & 6 & 0 & 7 & 6 & 4 \\
\hline class A-8b & 14 & 0 & 10 & 4 & 2 \\
\hline class A-8c & 12 & 2 & 5 & 3 & 5 \\
\hline class A-9a & 7 & 4 & 2 & 4 & 7 \\
\hline class A-9b & 13 & 0 & 6 & 3 & 2 \\
\hline school B $(n=107)$ & 16 & 13 & 18 & 23 & 37 \\
\hline class B-8a & 3 & 0 & 2 & 4 & 12 \\
\hline class B-8b & 1 & 3 & 4 & 4 & 7 \\
\hline class B-8c & 1 & 4 & 3 & 5 & 7 \\
\hline class B-9a & 5 & 3 & 6 & 7 & 4 \\
\hline class B-9b & 6 & 3 & 3 & 3 & 7 \\
\hline Gymnasium $(n=142)$ & 94 & 3 & 33 & 7 & 5 \\
\hline school C $(n=86)$ & 46 & 3 & 25 & 7 & 5 \\
\hline class C-8a & 12 & 1 & 6 & 1 & 1 \\
\hline class $\mathrm{C}-8 \mathrm{~b}$ & 10 & 1 & 8 & 4 & 1 \\
\hline class C-9a & 6 & 1 & 7 & 1 & 2 \\
\hline class C-9b & 18 & 0 & 4 & 1 & 1 \\
\hline school D $(n=56)$ & 48 & 0 & 8 & 0 & 0 \\
\hline class D-8a & 12 & 0 & 4 & 0 & 0 \\
\hline class D-8b & 14 & 0 & 2 & 0 & 0 \\
\hline class D-9a & 14 & 0 & 0 & 0 & 0 \\
\hline class D-9b & 8 & 0 & 2 & 0 & 0 \\
\hline
\end{tabular}

Note: $n=$ number of students

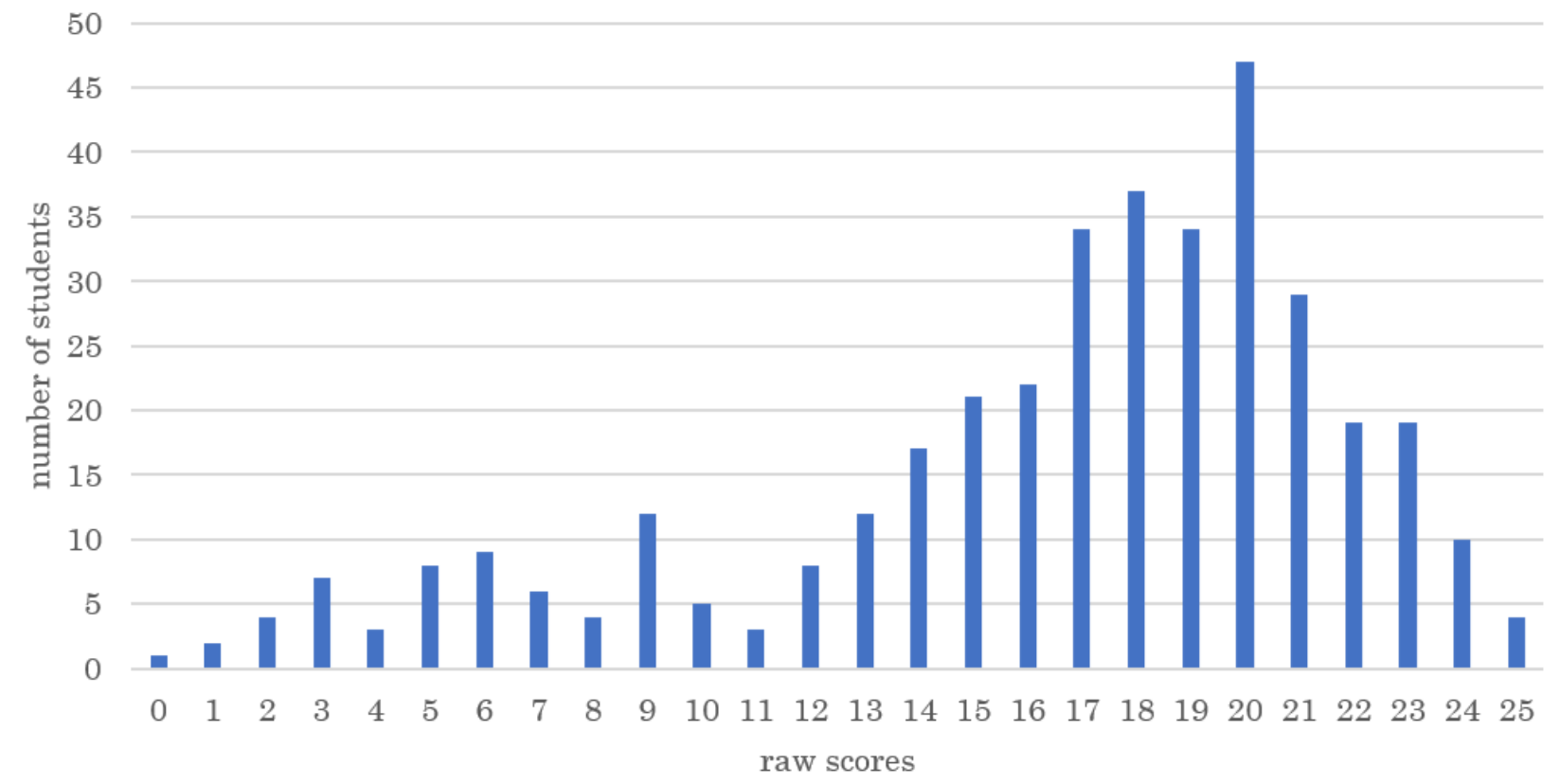

Figure 3. Distribution of general cognitive abilities

\section{General cognitive abilities}

Descriptive statistics for the variable general cognitive abilities confirmed the expected heterogeneity of the sample, showing a high standard deviation $(M=16.43, S D=5.50)$. The sample contained many students with high cognitive abilities as well as weak students (Figure 3). 
Differences in general cognitive abilities were statistically significant, Welch's $F(4,96.45)=28.85, p<.001, \eta^{2}=.24$. The results of the corresponding post-hoc analyses (see Table 4) are discussed in the following.

Based on the assumption that there is a stronger relationship between general cognitive abilities and conceptual knowledge than between general cognitive abilities and procedural knowledge, three hypotheses were tested:

1) Clusters with similar conceptual knowledge should not differ significantly in general cognitive abilities despite their different levels of procedural knowledge. This was the case both for the clusters with average conceptual knowledge (cluster 2 and cluster 3 ) and the clusters with low conceptual knowledge (cluster 4 and cluster 5).

2) The general cognitive abilities in cluster 1 (high conceptual knowledge) should differ significantly from the other clusters, which was also true.

3) The two clusters with average conceptual knowledge (cluster 2 and cluster 3) and the two clusters with low conceptual knowledge (cluster 4 and cluster 5) should differ significantly in general cognitive abilities. This could only be confirmed to a limited extent, as it held for cluster 3 but not for cluster 2 . Cluster 2 did not differ significantly in the general cognitive abilities from cluster 4 and cluster 5 .

Overall, these results only partially support the hypothesis that the individual differences in conceptual and procedural knowledge are related to general cognitive abilities.

\section{DISCUSSION}

In the following, central results of the present study are discussed, taking into account methodological aspects.

The results of the present study provide further evidence for the existence of individual differences in conceptual and procedural knowledge, as a five-cluster solution was identified. Since previous studies on individual differences in conceptual and procedural knowledge used different methodological approaches (e.g., residualized versus non-residualized scores), they show slightly different cluster solutions. However, clusters of individual differences are not directly comparable across different studies regardless, since a hierarchical cluster analysis generates subgroups depending on the sample (Bortz \& Schuster, 2010). In the following, the identified clusters are interpreted and discussed.

Cluster 1 comprised students whose conceptual and procedural knowledge were both on an equally high level. It was clearly the largest of the five clusters ( $n=162$ of $N=377$ overall). On the one hand, this corresponds with the high correlation of the two types of knowledge. On the other hand, this could be a consequence of the sample containing highly gifted students from one school who achieve very good results in all aspects of learning fractions.

Both cluster 2 and cluster 5 included students whose procedural knowledge is on average lower than would have been expected from their conceptual knowledge.

Cluster 2 was the smallest cluster $(n=22)$. Students who belong to this cluster have an average level of conceptual knowledge and a lower level of procedural knowledge than would have been expected from their conceptual knowledge. They succeeded quite well in expanding and simplifying fractions but showed deficits especially in the verbalization tasks and in the execution of fraction addition and subtraction. The vast majority of their errors were typical error patterns (e.g., adding fractions by adding the denominators and the numerators separately) and not careless errors as might have been expected. Obviously, these students were not able to transfer their conceptual knowledge into computational skills; or, put another way, their conceptual knowledge did not help them to avoid typical errors when calculating fraction tasks.

Overall, the analysis of cluster 2 might indicate that knowledge of fractions can be separated not only into a conceptual and a procedural factor but possibly is fragmented into smaller partial factors (Herden \& Pallack, 2000; Reinhold, 2019).

Cluster 5 was an average-sized cluster $(n=62)$ characterized by low conceptual knowledge and even lower procedural knowledge than would have been expected from conceptual knowledge. Cluster 5 represented a counterpart to cluster 1 as it comprised students who performed low in both types of knowledge.

Both cluster $3(n=81)$ and cluster $4(n=50)$ were of average size. The analysis of the task types showed a nearly parallel course for the two clusters, which can be interpreted in terms of gradual differences. These two clusters represented students whose procedural knowledge is higher than would have been expected from their conceptual knowledge. An explanation for this might lie in a way of teaching mathematics, which focuses on procedural knowledge rather than on conceptual knowledge. Textbook analyses indicate, for example, that most of the learning opportunities aim for procedural knowledge (in Singapore and Taiwan for the overall fraction unit: Yang, Reys, \& Wu, 2010; in Germany for fraction operations: Lenz, Holzäpfel \& Wittmann, 2019b; in the USA and Korea for multiplication and division of fractions: Son \& Senk, 2010).

In total, the results indicate that it does not seem plausible to base adaptive support strategies on the relative strengths and weaknesses of students' conceptual and procedural knowledge, as is sometimes suggested (Hallett et al., 2012; Hecht \& Vagi, 2012). A more differentiated consideration of the knowledge profiles is necessary in order to derive concrete support strategies from them. In particular, cluster 2 and cluster 5 showed lower procedural knowledge than expected from conceptual knowledge, which suggests that procedural knowledge should be fostered. However, the students' individual resources and needs differ between these two clusters. While students in cluster 5 need support in nearly all aspects, students in cluster 2 have some conceptual knowledge which can act as an appropriate basis to foster their procedural knowledge. Furthermore, the descriptive statistics show a high variance within the clusters, indicating that this classification is not sufficient for adaptive support.

The present study found effects of the school type, the school, and the class on cluster membership. That such patterns were empirically evident might be a consequence of the very heterogeneous sample. Previous studies seem to have analyzed more 
homogeneous samples, which might explain why such relationships addressing learning experiences were not evident at the empirical level (e.g., two schools of the same type in the same county in the study by Hallett et al., 2012). However, the sources of the observed relationships remain unclear. Differences in teaching objectives (curricular requirements, school profile) or teaching methods are just as conceivable as personality traits (e.g., general cognitive abilities) or social influences (catchment area, class structure).

Nevertheless, the identified class effects (although the classes in the secondary school sub-sample did not differ significantly in general cognitive abilities) support the hypothesis that teaching can influence individual differences in conceptual and procedural knowledge.

Considering the impact of general cognitive abilities on individual differences in conceptual and procedural knowledge, the fact that cluster 2 did not significantly differ from cluster 3 and cluster 4 in terms of general cognitive abilities to some extent reflects the German school system. In all three clusters students from Realschule were predominantly represented (this type of school is mainly attended by students with average general cognitive abilities), with fewer students from Gymnasium (with higher scores in general cognitive abilities).

\section{CONCLUSION}

Overall, the identified individual differences in conceptual and procedural fraction knowledge indicate that there are different ways to develop conceptual and procedural knowledge, as previously argued by others. This again challenges previous theoretical assumptions about the development of the two types of knowledge (procedures first, concepts first, iterative), which all postulate a common developmental relation between them.

Due to the cross-sectional design of this study, which is in line with previous research, it remains unclear whether the individual differences in conceptual and procedural knowledge reflect snapshots of certain developmental stages or indicate stable knowledge profiles. Further research is needed to clarify the developmental relations using longitudinal designs. Moreover, if the identified individual differences do indeed reflect stable knowledge profiles, it would be interesting to investigate to what extent students have the same knowledge profile in different mathematical fields.

\section{REFERENCES}

Anderson, J. R., Funke, J., Neuser-von Oettingen, K., \& Plata, G. (Eds.) (2013). Kognitive Psychologie [Cognitive Psychology]. Berlin: Springer. https://doi.org/10.1007/978-3-642-37392-3

Anderson, L. W., \& Krathwohl, D. R. (Eds.) (2001). A taxonomy for learning, teaching, and assessing. A re-vision of Bloom's taxonomy of educational objectives. New York: Longman

Baroody, A. J., \& Gannon, K. E. (1984). The development of the commutativity principle and economical addition strategies. Cognition and Instruction, 1, 321-339. https://doi.org/10.1207/s1532690xci0103_3

Baroody, A. J., Feil, Y., \& Johnson, A. R. (2007). An alternative reconceptualization of conceptual and procedural knowledge. Journal for Research in Mathematics Education, 38(2), 115-131. https://doi.org/10.2307/30034952

Bempeni, M., Poulopoulou, S., Tsiplaki, I., \& Vamvakoussi, X. (2018). Individual differences in fractions' conceptual and procedural knowledge: What about older students? Proceedings of PME 42, Umea, Schweden: PME.

Bortz, J., \& Schuster, C. (2010). Statistik für Human- und Sozialwissenschaftler [Statistics for human and social scientists]. Berlin, Heidelberg: Springer. https://doi.org/10.1007/978-3-642-12770-0

Briars, D., \& Siegler, R. S. (1984). A featural analysis of preschoolers' counting knowledge. Developmental Psychology, 20, 607-618. https://doi.org/10.1037/0012-1649.20.4.607

Bühl, A. (2016). SPSS 23. Einführung in die moderne Datenanalyse [Introduction to modern data analysis]. Hallbergmoos: Pearson.

Byrnes, J. P., \& Wasik, B. A. (1991). Role of conceptual knowledge in mathematical procedural learning. Developmental psychology, 27, 777-786. https://doi.org/10.1037/0012-1649.27.5.777

Cohen, J., Cohen, P., West, S. G., \& Aiken, L. S. (2013). Applied multiple regression/correlation analysis for the behavioral sciences. New York, London: Routledge. https://doi.org/10.4324/9780203774441

Crooks, N. M., \& Alibali, M. W. (2014). Defining and measuring conceptual knowledge in mathematics. Developmental Review, 34(4), 344-377. https://doi.org/10.1016/j.dr.2014.10.001

Döring, N., \& Bortz, J. (2016). Forschungsmethoden und Evaluation in den Sozial- und Humanwissenschaften [Research methods and evaluation in the social and human sciences]. Berlin, Heidelberg, Germany: Springer. https://doi.org/10.1007/978-3-64241089-5

Fuchs, L. S., Schumacher, R. F., Long, J., Namkung, J., Hamlett, C. L., \& Cirino, P. T. (2013). Improving at-risk learners' understanding of fractions. Journal of Educational Psychology, 105(3), 683-700. https://doi.org/10.1037/a0032446

Gabriel, F., Coche, F., Szucs, D., Carette, V., Rey, B., \& Content, A. (2013). A componential view of children's difficulties in learning fractions. Frontiers in Psychology, 4, 715. https://doi.org/10.3389/fpsyg.2013.00715 
Geary, D. C. (2004). Mathematics and learning disabilities. Journal of Learning Disabilities 37(1), 4-15. https://doi.org/10.1177/00222194040370010201

Geary, D. C., Boykin, A. W., Embretson, S., Reyna, V., Siegler, R., Berch D. B., \& Graban, J. (2008). Report of the task group on learning processes. In U.S. Department of Education (Ed.), The final report of the National Mathematics Advisory Panel. Washington D.C.: U.S. Department of Education.

Gilmore C. K., \& Papadatou-Pastou M. (2009). Patterns of individual differences in conceptual understanding and arithmetical skill: A meta-analysis. Mathematical Thinking and Learning, 11(1-2), 25-40. https://doi.org/10.1080/10986060802583923

Hallett, D., Nunes, T., \& Bryant, P. (2010). Individual differences in conceptual and procedural knowledge when learning fractions. Journal of Educational Psychology, 102, 395-406. https://doi.org/10.1037/a0017486

Hallett, D., Nunes, T., Bryant, P., \& Thorpe, C. M. (2012). Individual differences in conceptual and procedural fraction understanding: The role of abilities and school experience. Journal of Experimental Child Psychology, 113(4), 469-486. https://doi.org/10.1016/j.jecp.2012.07.009

Hecht, S. A., \& Vagi, K. J. (2010). Sources of group and individual differences in emerging fraction skills. Journal of Educational Psychology, 102, 843-859. https://doi.org/10.1037/a0019824

Hecht, S. A., \& Vagi, K. J. (2012). Patterns of strengths and weaknesses in children's knowledge about fractions. Journal of Experimental Child Psychology, 111(2), 212-229. https://doi.org/10.1016/j.jecp.2011.08.012

Hecht, S. A., Close, L., \& Santisi, M. (2003). Sources of individual differences in fraction skills. Journal of Experimental Child Psychology, 86, 277-302. https://doi.org/10.1016/j.jecp.2003.08.003

Heller, K. A., \& Perleth, C. (2000). KFT 4-12+ R Kognitiver Fähigkeitstest für 4. bis 12. Klassen. Manual [KFT 4-12+ R Cognitive Abilities Test4-12. Manual]. Göttingen: Hogrefe.

Herden, G., \& Pallack, A. (2000). Zusammenhänge zwischen verschiedenen Fehlerstrategien in der Bruchrechnung. Empirische Erhebung über 244 SchülerInnen der Klassen sieben von Gymnasien [Student errors in working with fractions. Empirical investigation among 244 students of grade 7]. Journal für Mathematik-Didaktik, 21, $259-279$. https://doi.org/10.1007/BF03338921

Hiebert, J., \& Lefevre, P. (1986). Conceptual and procedural knowledge in mathematics: An introductory analysis. In J. Hiebert (Ed.), Conceptual and procedural knowledge. The case of mathematics (pp. 1-27). Hillsdale, NJ: Erlbaum.

Hiebert, J., \& Wearne, D. (1996). Instruction, Understanding, and Skill in Multidigit Addition and Subtraction, Cognition and Instruction, 14(3), 251-283. https://doi.org/10.1207/s1532690xci1403_1

Holling, H., Preckel, F., \& Vock, M. (2004). Intelligenzdiagnostik. Göttingen: Hogrefe.

Jordan, N. C., Hansen, N., Fuchs, L. S., Siegler, R. S., Gersten, R., \& Micklos, D. (2013). Developmental predictors of fraction concepts and procedures. Journal of experimental child psychology, 116(1), 45-58. https://doi.org/10.1016/j.jecp.2013.02.001

Kerslake, D. (1986). Fractions: Children's strategies and errors: A report of the strategies and errors in Secondary Mathematics Project. Windsor, UK: NFER-Nelson.

Kieren, T. E. (1976). On the mathematical, cognitive, and instructional foundations of rational numbers. In R. A. Lesh (Eds.), Number and measurement (pp. 101-150). Columbus, $\mathrm{OH}$ : Eric.

Kilpatrick, J., Swafford, J., \& Findell, B. (Eds.) (2001). Adding it up. Helping children learn mathematics. Washington, DC: National Academy Press.

Lenz, K., Dreher, A., Holzäpfel, L., \& Wittmann, G. (2019a). Are conceptual and procedural knowledge empirically separable? - The case of fractions. British Journal of Educational Psychology. https://doi:10.1111/bjep.12333

Lenz, K., Holzäpfel, L., \& Wittmann, G. (2019b). Aufgaben als Lerngelegenheiten für konzeptuelles und prozedurales Wissen zu Brüchen - Eine vergleichende Schulbuchanalyse [Tasks as learning opportunities for conceptual and procedural fraction knowledge -A comparative textbook analysis]. mathematica didactica 42(2), 105-121.

Lienert, G. A. (1969). Testaufbau und Testanalyse [Test construction and test analysis]. Weinheim: Beltz.

Lortie-Forgues, H., Tian, J., \& Siegler, R. (2015). Why is learning fraction and decimal arithmetic so difficult? Developmental Review, 38, 201-221. https://doi.org/10.1016/j.dr.2015.07.008

Malle, G. (2004). Grundvorstellungen zu Bruchzahlen. Mathematik lehren, (123), 4-8.

Padberg, F., \& Wartha, S. (2017). Didaktik der Bruchrechnung. Gemeine Brüche - Dezimalbrüche [Didactics of fractions. Common fractions - decimal fractions] Berlin, Germany: Springer Spektrum. https://doi.org/10.1007/978-3-662-52969-0

Peck, D., \& Jencks, S. (1981). Conceptual issues in the teaching and learning of fractions. Journal for Research in Mathematics Education, 12, 339-348.

Prediger, S., Barzel, B., Leuders, T., \& Hußmann, S. (2011). Systematisieren und Sichern. Nachhaltiges Lernen durch aktives Ordnen [Systemizing and consolidating knowledge. Lasting learning through active organization]. Mathematik lehren, 164, 2-9.

Reinhold, F. (2019). Wirksamkeit von Tablet-PCs bei der Entwicklung des Bruchzahlbegriffs aus mathematikdidaktischer und psychologischer Perspektive. Eine empirische Studie in Jahrgangsstufe 6. [Effectiveness of tablet PCs in the development of the fractional number concept from a mathematics educational and psychological perspective]. Wiesbaden: Springer Spektrum. https://doi.org/10.1007/978-3-658-23924-4 
Rittle-Johnson, B., \& Schneider, M. (2015). Developing conceptual and procedural knowledge of mathematics. In R. C. Kadosh \& A. Dowker (Eds.), The Oxford handbook of numerical cognition (pp. 1102-1118). Oxford, UK, New York, NY: Oxford University Press. https://doi.org/10.1093/oxfordhb/9780199642342.013.014

Rittle-Johnson, B., Siegler, R. S., \& Alibali, M. W. (2001). Developing conceptual understanding and procedural skill in mathematics. An iterative process. Journal of Educational Psychology, 93, 346-362. https://doi.org/10.1037/0022-0663.93.2.346

Schneider, M., \& Stern, E. (2010). The developmental relations between conceptual and procedural knowledge: A multimethod approach. Developmental Psychology, 46(1), 178-192. https://doi.org/10.1037/a0016701

Schneider, M., Rittle-Johnson, B., \& Star, J. R. (2011). Relations between conceptual knowledge, procedural knowledge, and procedural flexibility in two samples differing in prior knowledge. Developmental Psychology, 47, $1525-1538$. https://doi.org/10.1037/a0024997

Siegler, R. S., \& Lortie-Forgues, H. (2015). Conceptual knowledge of fraction arithmetic. Journal of Educational Psychology, 107, 909-918. https://doi.org/10.1037/edu0000025

Son, J.-W., \& Senk, S. L. (2010). How reform curricula in the USA and Korea present multiplication and division of fractions. Educational Studies in Mathematics, 74(2), 117-142. https://doi.org/10.1007/s10649-010-9229-6

Thorndike, R. L., \& Hagen, E.P. (1971). Cognitive Abilities Test. Boston: Houghton-Mifflin.

Vamvakoussi, X., Bempeni, M., Poulopoulou, S., \& Tsiplaki, I. (2019). Theoretical and methodological issues in the study of conceptual and procedural knowledge: Reflections on a series of studies on Greek secondary students' knowledge of fractions. Educational Journal of the University of Patras UNESCO Chair, 6(2), 82-96.

Wiedenbeck, M., \& Züll, C. (2010). Clusteranalyse. In C. Wolf \& H. Best (Eds.), Handbuch der sozialwissenschaftlichen Datenanalyse [Manual of social science data analysis] (p. 525-552). Wiesbaden: VS Verlag für Sozialwissenschaften. https://doi.org/10.1007/978-3-531-92038-2_21

Yang, D., Reys, R., \& Wu, L. (2010). Comparing the development of fractions in the fifth- and sixth-graders' textbooks of Singapore, Taiwan, and the USA. School, Science and Mathematics 110(3), 118-127. https://doi.org/10.1111/j.1949-8594.2010.00015.x 